TecnoLógicas

ISSN-p 0123-7799

ISSN-e 2256-5337

Vol. 21, No. 42, pp. 211-229

Mayo-agosto de 2018

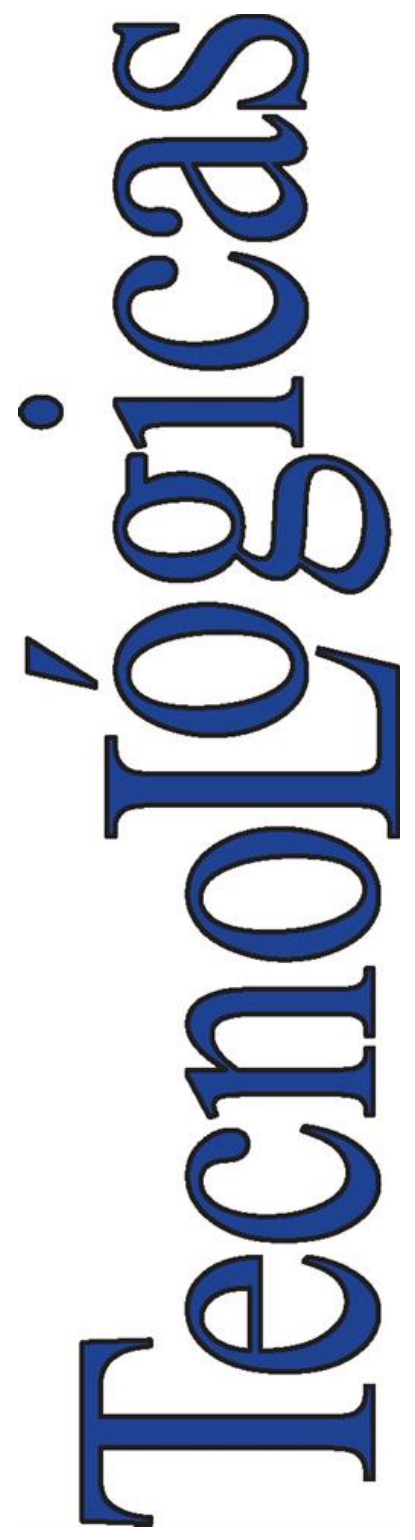

(C) Copyright 2015 por autores y Tecno Lógicas Este trabajo está licenciado bajo una Licencia Internacional Creative Commons Atribución (CC BY)

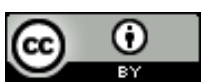

Artículo de Investigación/Research Article

\section{Evaluación y comparación de técnicas para la reconstrucción de la función de dispersión de punto de imágenes degradadas por difuminación lineal uniforme}

\section{Evaluation and comparison of techniques for reconstructing the point spread function of images blurred by uniform linear motion}

\author{
Jimmy A. Cortés-Osorio ${ }^{1}$, Cristian D. López-Robayo ${ }^{2}$ y \\ Nathalia Hernández-Betancourt ${ }^{3}$
}

Recibido: 18 de agosto de 2017

Aceptado: 05 de marzo de 2018

Cómo citar / How to cite

J. A. Cortés-Osorio, C. D. López-Robayo y N. Hernández-Betancourt, Evaluación y comparación de técnicas para la reconstrucción de la función de dispersión de punto de imágenes degradadas por difuminación lineal uniforme. TecnoLógicas, vol. 21, no. 42, pp.211$229,2018$.

1 Ingeniero Electricista, Magíster en Instrumentación Física, Departamento de Física, Facultad de Ciencias Básicas, Universidad Tecnológica de Pereira,

Pereira-Colombia, jacoper@utp.edu.co

2 Ingeniero Electrónico, Universidad Tecnológica de Pereira, PereiraColombia, crdalopez@utp.edu.co

3 Ingeniera Física, Universidad Tecnológica de Pereira, Pereira-Colombia, nathhernandez@utp.edu.co 


\title{
Resumen
}

En el área del procesamiento digital de imágenes, es frecuente encontrar diferentes tipos de degradaciones, como lo es la difuminación por movimiento (motion blur), la cual es causada por el movimiento relativo entre la cámara y el objeto observado. Esto produce sobre la imagen una estela de bajo contraste que sigue la trayectoria del movimiento. Si la velocidad relativa es constante y el desenfoque es invariante sobre toda la imagen, la difuminación causada puede ser modelada por medio de la Función de Dispersión de Punto (PSF) usando los parámetros de longitud y ángulo de la estela dejada. Este trabajo evaluó la exactitud en la estimación de dichos parámetros y la robustez al Ruido Aditivo Blanco Gaussiano de un grupo de estrategias espaciales y en frecuencia para la reconstrucción de la PSF, además se consideró el tiempo de ejecución de los algoritmos presentados. Se usaron 20 imágenes de 512x512 píxeles degradadas sintéticamente. Se evaluaron cinco de las técnicas más conocidas para la estimación del ángulo y tres para la longitud. Los resultados experimentales revelaron que las técnicas con los errores absolutos promedio más bajos para la estimación del ángulo y la longitud de la PSF en imágenes sin ruido son la Transformada Cepstrum 2D y la Transformada Cepstrum 1D, respectivamente.

\section{Palabras clave}

Cepstrum, Difuminación por movimiento, Filtros adaptativos, Función de Dispersión, Movimiento lineal uniforme, Reconstrucción, Transformada de Hough, Transformada de Radon.

\begin{abstract}
In the field of digital image processing, it is common to find different types of degradation. One of them is motion blur, which is caused by the relative movement between the camera and the observed object. It produces a low-contrast trace on the image that follows the trajectory of the movement. If the relative velocity is constant and the blur is invariant across the entire image, the resulting blur can be modeled by means of the Point Spread Function (PSF) and using the trace's length and the angle parameters. This work evaluated the accuracy of the estimation of the angle and length parameters, and the robustness to Additive White Gaussian Noise of a set of spatial and frequency approaches for reconstructing the PSF. It is important to highlight that the algorithms' processing time was also considered. In total, $20512 \times 512$ pixels synthetically-degraded images were used. Besides, five of the best-known techniques for estimating the angle and three for the length of the PSF were evaluated. The experimental results revealed the techniques with the lowest absolute mean error for estimating the angle and the length of the PSF in noise-free images: 2D Cepstrum Transform and 1D Cepstrum Transform, respectively.
\end{abstract}

\section{Keywords}

Cepstrum, Motion blur, Steerable Filters, Linear Point Spread Function, Reconstruction, Hough transform, Radon transform. 


\section{INTRODUCCIÓN}

La reconstrucción de la Función de Dispersión de Punto (PSF) debido a la difuminación causada por movimiento (motion blur) ha sido un tema de interés en diferentes áreas en los últimos años, como lo es en la oftalmología [1] y en las imágenes diagnósticas de ultrasonido [2]. También ha sido estudiado para la estimación de velocidades a partir de una única imagen [3], [4], [5], [6] y en la industria [7]. En los últimos años, muchas investigaciones se han realizado para identificar con mayor exactitud los parámetros de la PSF. Yitzhaky, planteó una metodología para la estimación del ángulo de la PSF por medio de un kernel direccional derivativo tangencial [8]. [9] estimaron el ángulo de la $P S F$ por medio de la transformada de Radon en 2D aplicada sobre el logaritmo de la transforma de Fourier 2D. Además, estimaron la longitud de la PSF al identificar la distancia entre dos ceros sucesivos en el patrón generado por la transformada de Radon [9]. [10] realizaron la estimación del ángulo de la PSF por medio de la transformada de Hough sobre el logaritmo de la transformada de Fourier 2D [10]. Por otro lado, Rekleitis aplicó una familia de filtros adaptativos, como el filtro Gaussiano, sobre el logaritmo de la transformada de Fourier para la estimación del ángulo de la PSF [11]. Aquí se debe destacar que una de las técnicas más mencionadas en la literatura científica en el área del análisis de señales es el Cepstrum [12], [13], [14], [15]. Su dominio puede usarse para la separación de los componentes de la PSF de las componentes de la imagen. Alternativamente, Shah y Dalal formularon una metodología para estimar la longitud y el ángulo de la PSF en el dominio del Cepstrum al que denominaron Cepstrum modificado [16], [17]. También se han usado técnicas de aprendizaje de máquina como las Máquinas de Soporte Vectorial Multiclase (SVM) y Redes Neuronales Artificiales (ANN) para clasificar algunas características de las imágenes para longitudes diferentes de la PSF [18], [19]. Por último, existe un conjunto de técnicas alternativas emergentes basadas histogramas de gradientes orientados [20] y estadística de la imagen [21]. En este artículo, se evalúan con mayor detalle y rigor las técnicas más destacas en el estado del arte para la identificación de los parámetros de la PSF relacionada con la difuminación por movimiento lineal uniforme, considerando el Ruido Blanco Aditivo Gaussiano (AWGN) y sus tiempos de ejecución. Estos aspectos no han sido abordados con rigurosidad en la literatura científica encontrada por los autores.

\subsection{Modelo de degradación de la imagen}

La difuminación (blur) es una forma de reducción del contenido de alta frecuencia de la imagen que puede ser causado, entre otras causas, por imperfecciones en la lente, turbulencia atmosférica o por el movimiento relativo entre la escena y la cámara (motion blur). Este último tipo de degradación mecánica se puede presentar en forma de translación, rotación o como un cambio de escala [22].

La base de formación de una imagen puede ser explicada mediante la Función de Dispersión de Punto (PSF), la cual puede entenderse como la Función de Transferencia del Sistema Óptico. Esta indica cómo una fuente puntual, monocromática, y coherente de luz resulta en un punto difuminado en el dominio del espacio al pasar por el sistema (Respuesta a la Función Impuso Unitario). Es decir, la imagen resultante real no es necesariamente una copia perfecta de la fuente de luz puntual, sino que esta presenta una difuminación [23]. La degradación de una imagen se puede modelar por (1):

$$
g(x, y)=I(x, y) * h(x, y)+n(x, y)
$$

Donde $n(x, y)$ es el ruido $\mathrm{y}$ * es la operación de convolución entre la imagen no 

degradadas por difuminación lineal uniforme

degradada $I(x, y)$ y la PSF $h(x, y)$. De esta manera, se tiene como resultado la imagen degradada $g(x, y)$ por la Función de Dispersión de Punto $h(x, y)$. En esta investigación, la PSF es la Función de Transferencia que modela la difuminación (motion blur) que afecta a la imagen.

\subsection{Estimación de los parámetros}

A partir de la definición de una imagen degradada en el dominio del espacio, como se mostró en (1), el modelo se puede expresar como una multiplicación punto a punto en el dominio de frecuencia. Por lo anterior, se puede obtener una definición análoga en el dominio de la frecuencia sin considerar el ruido, como se muestra en (2).

$G(u, v)=I(u, v) H(u, v)$
Donde $G(u, v)$ es el resultado de la multiplicación punto a punto en frecuencia (Transformada de Fourier en dos dimensiones) de la imagen no degradada $I(u, v)$ con la Transformada Óptica de Fourier (OFT) $H(u, v)$. Para calcular los parámetros de la PSF se deben considerar las variables como se muestra en la Fig. 1.

Cuando el objeto se mueve a una velocidad relativa constante durante la exposición de la cámara, se produce la difuminación por movimiento. En la escena mostrada en la Fig. 1 se observa una estela de baja energía que contiene información del movimiento relacionada con la longitud de la estela $\mathrm{L}$ y el ángulo $\theta$ de la misma [24]. La PSF para el movimiento lineal uniforme se puede modelar de forma espacial como (3).

La respuesta en frecuencia de $h(x, y)$, dada por la Transformada de Fourier de la función Rectangular, está dada por la función SINC que se muestra en (4).

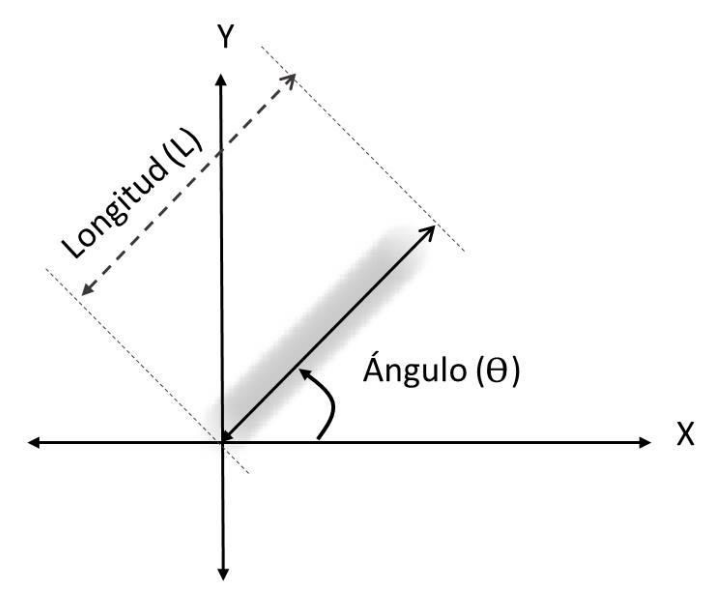

Fig. 1. Diagrama ilustrativo del desenfoque lineal por movimiento. Fuente: autores.

$$
\begin{gathered}
h(x, y)=\left\{\begin{array}{r}
\frac{1}{L} 0 \leq|x| \leq L \cos (\theta) ; y=L \sin (\theta) \\
0 \text { otro caso }
\end{array}\right. \\
H(u, v)=\operatorname{sinc}(\pi L(u \cos (\alpha)+v \sin (\alpha)))
\end{gathered}
$$


Evaluación y comparación de técnicas para la reconstrucción de la función de dispersión de punto de imágenes degradadas por difuminación lineal uniforme

En conclusión, si se transforma una imagen degradada por movimiento uniforme al dominio de la frecuencia (Espectro de Potencia de Fourier), es posible observar el efecto de la difuminación sobre la imagen e identificar los parámetros de la PSF. En la Fig. 2. Se puede observar que las líneas paralelas dominantes en el espectro de Fourier de la imagen son ortogonales al ángulo de la difuminación, mientras, la longitud está ligada a la distancia entre las líneas (distancia entre lóbulos laterales de la función SINC). Cuanto más cercanas estén las líneas entre sí, mayor es la longitud de la difuminación [24], [10]. Debido a lo mencionado anteriormente, la tarea de estimación del ángulo se encuentra en la identificación de la orientación de las líneas, y la estimación de la longitud está relacionada con la identificación de la distancia entre ellas. Sí se conoce el ángulo y la longitud de la PSF es posible reconstruir la imagen original por medio de la deconvolución entre la imagen con degradación y la PSF estimada [25], [21]. A manera de ejemplo, la Fig. 3 muestra el efecto de la degradación sintética sobre la imagen de Lenna (Fig. 3(a)) en el dominio de la frecuencia.

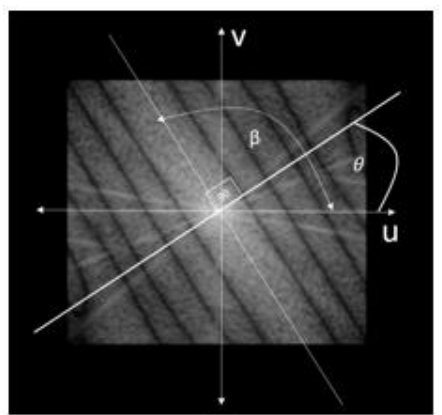

(a)

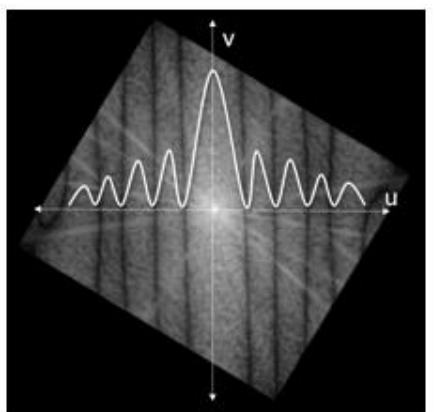

(b)

Fig. 2. Función SINC (4). (a) Muestra como calcular el ángulo de la PSF a partir del patrón de Fourier. (b) Ilustra el patrón rotado con un trazo de la Función Sinc (4) sobre la imagen. Fuente: autores.

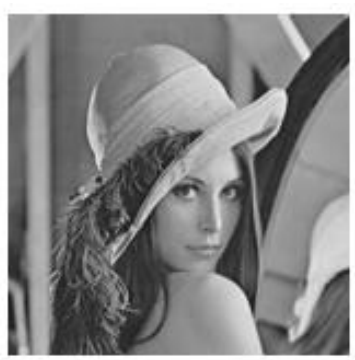

(a)

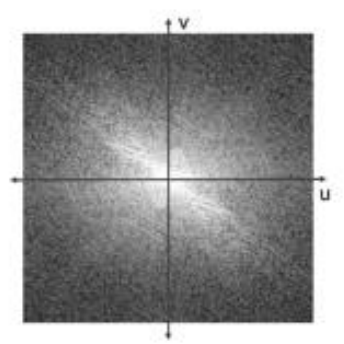

(c)

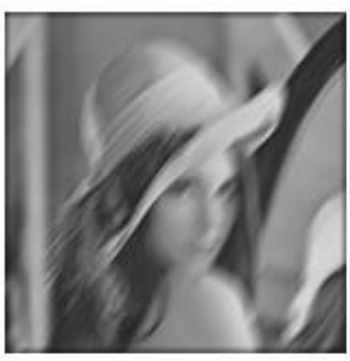

(b)

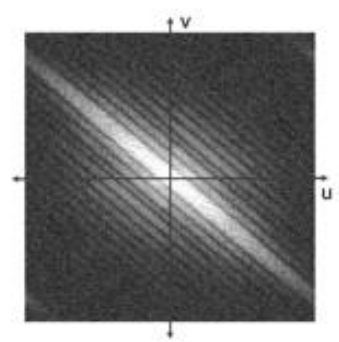

(d)

Fig. 3. Efectos de la degradación sobre la imagen de Lenna. (a) Imagen original de Lenna no degradada. (b) Imagen de Lenna degradada con una difuminación de 30 píxeles a 50 grados. (c) Espectro de Potencia de Fourier de la imagen original. (d) Espectro de Potencia de Fourier de la imagen degradada. Fuente: autores. 


\section{METOdOLOGíA}

\subsection{Estimación del ángulo de la PSF}

En esta sección se mostrarán los métodos seleccionados para la identificación del ángulo de la PSF, como: Transformada de Hough, Transformada de Radon, Filtro Adaptativo Gausiano, Filtro Adaptativo Gabor y Cepstrum 2D.

\subsubsection{Transformada de Hough}

El espacio de la transformada de Hough está basado en la representación Hessiana de una línea (5):

$\rho=x \cos \theta+y \sin \theta$

Donde $(x, y)$ son las coordenadas de un punto de la línea a considerar, $\theta$ es el ángulo formado entre la línea y un trazo perpendicular de longitud $\rho$ que inicia desde el origen cartesiano hasta la línea de interés. En el espacio transformado de Hough se localiza el ángulo $\theta$ como el pico o el punto más brillante.

Para obtener el ángulo de la dirección de la PSF, primero, se debe realizar la transformada de Fourier de la imagen. Seguidamente, sobre el logaritmo de la transformada de Fourier de esta, se realiza la transformada de Hough para obtener la dirección de las líneas paralelas dominantes. Por último, el ángulo de la PSF está dado por $90-\theta$ en grados [10], [26]. La Fig. 4 muestra el resultado de aplicar la transformada de Hough sobre el espectro de Fourier con una imagen degradada con difuminación sintética orientada a 35 grados.

\subsubsection{Transformada de Radon}

La transformada de Radon, para este caso, es la proyección del Espectro de Fourier en dos dimensiones sobre una línea rotada a diferentes ángulos $\theta$. Este último parámetro tiene igual significado que el indicado en la transformada de Hough. Cada una de las proyecciones sobre las líneas está representada en la transformada de Radon como picos, que determinan la ubicación de las líneas originales de la imagen; en otras palabras, la transformada de Radon es una integral de línea [9]. La transformada de Radon en el dominio discreto en $2 \mathrm{D}$ está definida por (6).

$g(\rho, \theta)=\sum_{x=0}^{M-1} \sum_{y=0}^{N-1} f(x, y) \delta(x \sin \theta+y \cos \theta-\rho)$

Donde $f(x, y)$ es la imagen, $M$ es el número de columnas de la imagen, $N$ es el número de filas de la imagen, $\delta$ es el delta de Dirac, $\theta$ es el ángulo formado entre la línea y una línea perpendicular que inicia desde el origen cartesiano hasta la línea, y $\rho$ es la distancia de la línea perpendicular. Para determinar el ángulo de la PSF con la transformada de Radon, primero, se debe realizar la transformada de Fourier de la imagen degradada. Posteriormente, se realiza la transformada de Radon sobre el logaritmo del espectro. El punto más brillante $(\rho, \theta)$ en la matriz resultante de la transformada de Radon está relacionado con el ángulo $\theta$ de la dirección de las líneas paralelas dominantes [27]. La Fig. 5 muestra el resultado de aplicar la Transformada de Radon sobre el espectro de Fourier de una imagen degradada con difuminación sintética por movimiento orientada a 50 grados

\subsubsection{Filtros adaptativos}

Los filtros adaptativos son comúnmente usados para la detección de bordes, compresión de imágenes, análisis de texturas, entre otras aplicaciones en el área del Procesamiento Digital de Imágenes (PDI) [28]. Rekleitis expuso un método para determinar la orientación de la PSF a partir de la rotación de un filtro Gaussiano sobre el 
Evaluación y comparación de técnicas para la reconstrucción de la función de dispersión de punto de imágenes degradadas por difuminación lineal uniforme

logaritmo del espectro de Fourier [11]. Para determinar la orientación de las líneas, se promedia la respuesta de energía del filtro sobre el Espectro de Potencia de Fourier de la imagen degradada en cada ángulo; al final, la orientación de las líneas determinantes del ángulo $\theta$ de la PSF está determinada en el ángulo donde se haya obtenido la respuesta de energía más alta. El kernel del filtro adaptativo Gaussiano está modelado por (7). Donde; FG representa el filtro, $k_{a}, k_{b}$ y $k_{c}$ son funciones de interpolación, $G_{2 a}, G_{2 b}$ y $G_{2 c}$ son paráme- tros de la segunda derivada de la función gaussiana.

De forma análoga, el kernel de la parte real del filtro adaptativo Gabor está modelado por (8). Donde; $\phi$ es la fase, $F G$ es el filtro, $\hat{x}$ es una función de interpolación, $\lambda$ es la longitud de onda y $K$ es un parámetro de escala del filtro de Gabor. Para detallar el desglose de los términos de la ecuación del filtro Gaussiano y Gabor, refiérase a [11], [28], [29], [30].

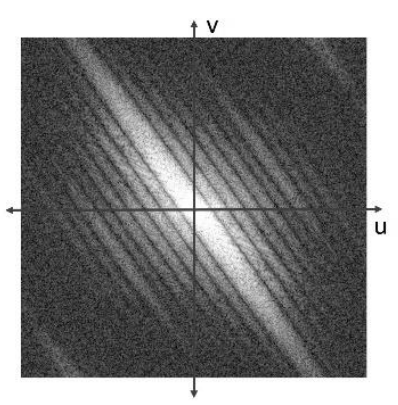

(a)

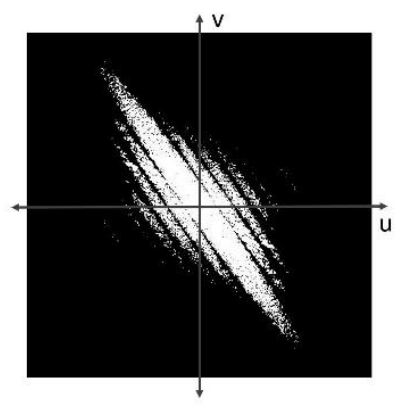

(b)

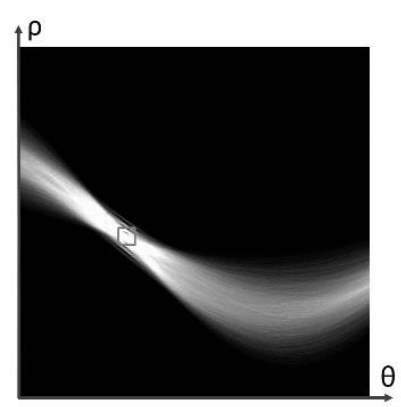

(c)

Fig. 4. Transformada de Hough sobre el Espectro de Potencia de Fourier de la imagen de Lenna degradada. (a) Espectro de Potencia de Fourier de Lenna degradada con una longitud de 25 píxeles a un ángulo de 35 grados. (b) Espectro de Potencia de Fourier binarizado con un umbral de 0,6. (c) Transformada de Hough del espectro binarizado, Fuente: autores.

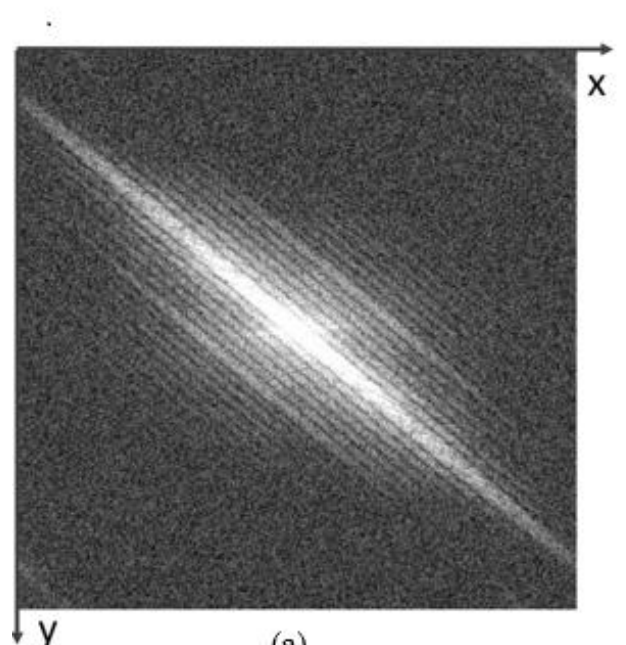

(a)

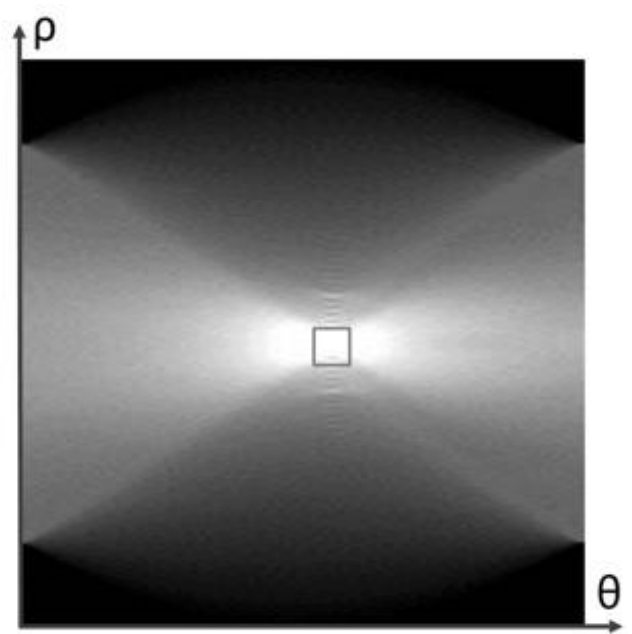

(b)

Fig. 5. Transformada de Radon sobre el espectro de Fourier de la imagen de Lenna degradada. (a) Espectro de Potencia de Fourier de Lenna degradada con una longitud de 55 píxeles a un ángulo de 50 grados. (b) Transformada de Radon sobre el espectro de Fourier (a), Fuente: autores. 


\subsubsection{Cepstrum 2D}

El dominio del Cepstrum es utilizado para la separación de las componentes de la degradación de la imagen [13]. La transformada de Cepstrum está definida por (9).

Donde $g(x, y)$ es la imagen con difuminación, $F$ es la transformada de Fourier, $\log$ es el logaritmo natural del valor absoluto de la transformada de Fourier y $F^{-1}$ es la transformada inversa de Fourier. Por otro lado, los investigadores Shan y Dalal [16], [17] propusieron un dominio basado en Cepstrum al que denominaron "Cepstrum modificado", que está definido por (10).
Con la imagen degrada en el dominio del Cepstrum, se realiza la técnica de bit plane slicing para extraer el cuarto bit $\mathrm{y}$ así binarizar la imagen. El ángulo en el dominio del Cepstrum 2D puede ser estimado a partir de la transformada de Hough sobre la Fig. 6(c). Por último, el ángulo de la PSF está dado por $180-\theta$ en grados. Los autores presentados en [16], [17] usaron para la binarización el cuarto bit, pero, en este caso, se usó el sexto bit en la binarización, ya que, se obtuvo un mejor resultado.

$$
\begin{gathered}
F G=k_{a}(\theta) G_{2 a}-k_{b}(\theta) G_{2 b}+k_{c}(\theta) G_{2 c} \\
F G=K \cos \left(\frac{2 \pi \hat{x}(\theta)}{\lambda}+\phi\right) \\
C\{g(x, y)\}=F^{-1}\{\log |F(g(x, y))|\} \\
C\{g(x, y)\}=\log \{|F\{\log |F(g(x, y))|\}|\}
\end{gathered}
$$

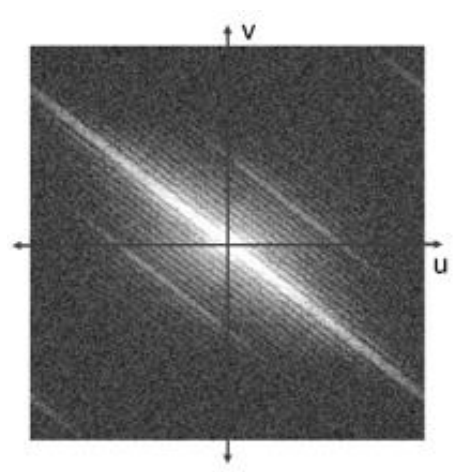

(a)

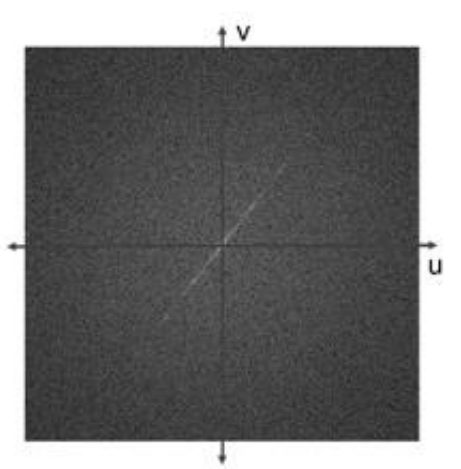

(b)

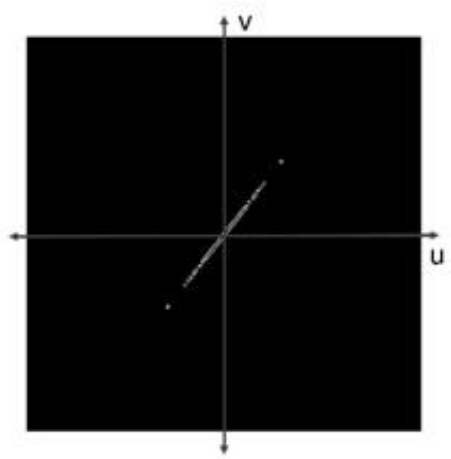

(c)

Fig. 6. Efecto de la degradación en el dominio del Cepstrum en dos Dimendiones. (a) Espectro de Potencia de Fourier de Lenna degradada con una longitud de 60 píxeles a un ángulo de 52 grados. (b) Cepstrum 2D de (a). (c) Cepstrum binarizado con el sexto bit, Fuente: autores. 


\subsection{Estimación de la longitud de la PSF}

En esta sección se mostrarán algunos métodos para la identificación de la longitud de la PSF, como: Función de Auto Correlación (ACF), Transformada de Radon y el Cepstrum en una dimensión.

\subsubsection{ACF}

La correlación es la relación entre dos (o más) señales; esta se puede usar para determinar la dependencia entre las señales que intervienen. De forma análoga, la Función de Auto Correlación (ACF) cuantifica cuanto se relacionan dos muestras de un mismo proceso. La función de auto correlación está definida por (11):

$\operatorname{ACF}(\tau)=\sum_{i=0}^{i-1-\tau} I(i) I(i+\tau)$

En este caso, $I(i)$ es un vector con la misma orientación de la difuminación, $I(i+\tau)$ es una versión del mismo vector pero con desplazamiento $T$. El valor de $T$ que maximice la función de auto correlación corresponde a la longitud de la $P S F$ [31].

Para determinar la longitud de la PSF a partir de la función de auto correlación se debe realizar la convolución entre el kernel derivativo tangencial propuesto en [8] con la orientación $\theta$ sobre la imagen degradada para obtener la derivada direccional. Luego se ubica el ángulo para el cual la energía es mínima. Posteriormente se rota la imagen y se realiza la función de auto correlación sobre cada fila y se promedia. Por último, se ubica el punto donde el valor de la señal sea mínimo para identificar la longitud de la PSF. La ecuación (12) presenta el kernel derivativo tangencial usado para hallar la derivada direccional de la imagen.

$D(i, j)=\left[\begin{array}{c}-11-\tan (\theta) \\ 0 \tan (\theta)\end{array}\right]$

La Fig. 7 muestra el efecto del kernel derivativo tangencial sobre una imagen degradada.

\subsubsection{Transformada de Radon}

La aproximación a la longitud de la PSF a partir de la transformada de Radon, propone, en primera instancia, determinar la orientación de las líneas del espectro a partir de la transformada de Radon. Posteriormente, rotar la imagen con el ángulo estimado, luego, colapsar el Espectro de Potencia de Fourier 2D sobre el eje u para

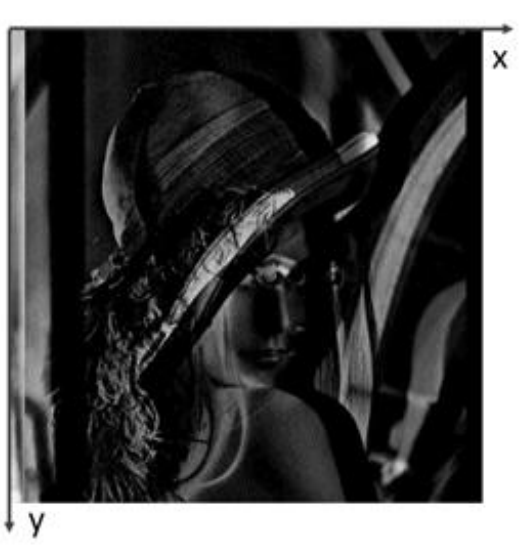

(a)

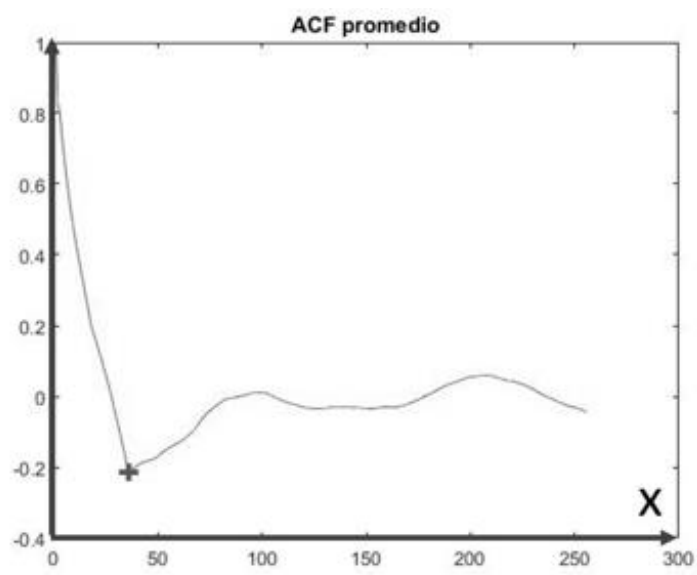

(b)

Fig. 7. Método de ACF para esitmación dela longitud. (a) Convolución entre el kernel derivativo tangencial con orientación cero sobre Lenna degradada con una longitud de 35 píxeles a un ángulo de cero grados. (b) Promedio normalizado de la función de auto correlación de cada una de las filas de la imagen (a). Fuente: autores. 
Evaluación y comparación de técnicas para la reconstrucción de la función de dispersión de punto de imágenes degradadas por difuminación lineal uniforme

obtener una representación en una dimensión (1D). Por último, identificar los mínimos relativos a partir de la derivada del espectro $1 \mathrm{D}$ y promediar la distancia entre ellos para estimar la longitud de la PSF [32], [33]. La Fig. 8 muestra la relación existente entre las zonas oscuras y los mínimos relativos con orientación de cero grados.

\subsubsection{Cepstrum 1D}

Para estimar la longitud de la PSF a partir del dominio del Cepstrum, se requiere, determinar la orientación de las líneas del Espectro de Potencia de Fourier por medio de la transformada de Radon. Lue- go, rotar la imagen con la orientación estimada, para después, colapsar el espectro en $2 \mathrm{D}$ sobre el eje u para obtener el espectro de Fourier 1D. Posteriormente, se realiza la transformada de Fourier 1D sobre la señal y se halla el valor absoluto para evitar puntos negativos, en este punto se encuentra la señal en el domino del Cepstrum en 1D; se aplicó una ventana a la señal desde los primeros cinco valores para atenuar el efecto de los contenidos de baja frecuencia, al final, la longitud de la PSF está dada por el punto donde se encuentre el máximo valor de la señal [34]. En la Fig. 9 se puede apreciar la forma de la señal en el dominio del Cepstrum en 1D.

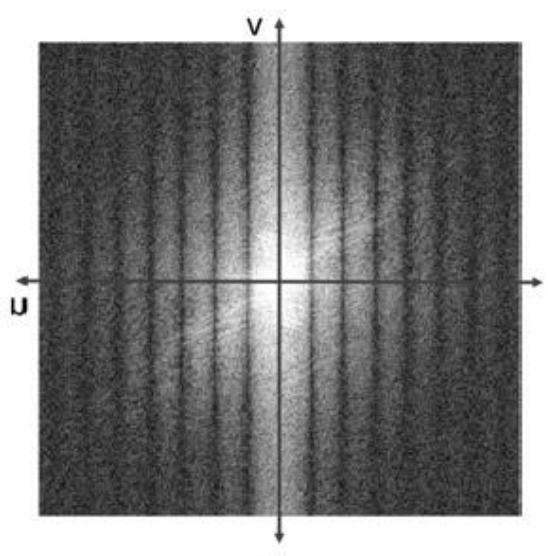

(a)

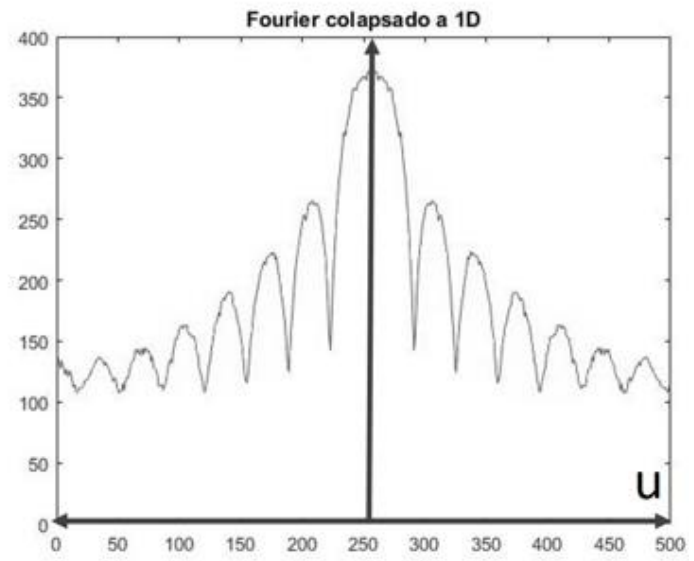

(b)

Fig. 8. Método de Radon para la estimación de la longitud. (a) Espectro de Potencia de Fourier de Lenna degradada con una longitud de 15 píxeles a un ángulo de 0 grados. (b) Espectro de Potencia de Fourier colapsada sobre el eje u. Fuente: autores.

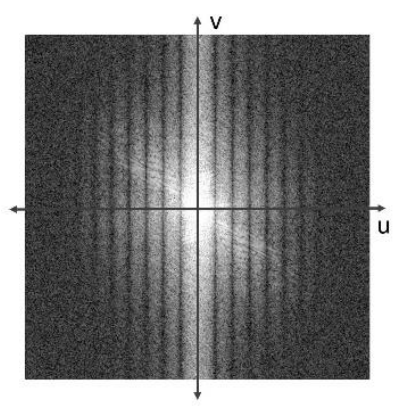

(a)

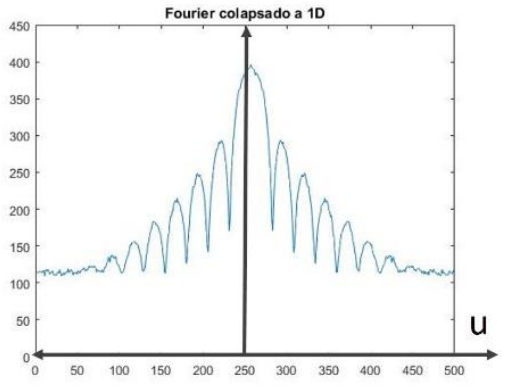

(b)

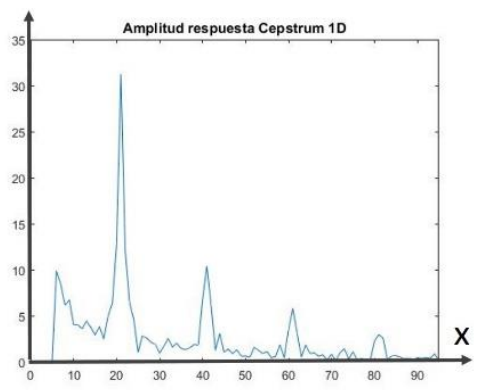

(c)

Fig. 9. Espectro de Fourier de Lenna degradada con una longitud de 20 píxeles a un ángulo de 0 grados. (b) Espectro de Fourier colapsado sobre el eje u (c) Señal en el dominio del Cepstrum 1D. Fuente: autores. 
Evaluación y comparación de técnicas para la reconstrucción de la función de dispersión de punto de imágenes degradadas por difuminación lineal uniforme

\subsection{Evaluación de técnicas}

Para la evaluación de las técnicas se utilizó la base de datos de la Universidad del Sur de California (USC-SIPI) [35], de la cual se tomaron 20 imágenes con una resolución de $512 \times 512$ con 8 píxeles de profundidad. Esta base de datos es reconocida y ha sido utilizada por más de 30 años en la evaluación de técnicas de procesamiento de imágenes, debido a que las imágenes cuentan con altos contenidos de alta y baja frecuencia y es posible realizar trazabilidad sobre ellas para la reproducción de los experimentos. Mediante su uso, se realizó la evaluación de técnicas de análisis en el dominio del espacio y la frecuencia para la estimación del ángulo y la longitud de PSF. La Fig. 10 muestra las imágenes seleccionadas de la base de datos usadas para la investigación.

Para la estimación del ángulo, se evaluaron las siguientes técnicas: Transformada de Hough, Transformada de Radon, Filtro Adaptativo Gaussiano, Filtro Adaptativo Gabor y Cepstrum 2D. Para realizar esta estimación se estableció la longitud de la PSF de 55 píxeles y se hicieron variacio- nes del ángulo desde uno hasta noventa grados, con incrementos de un grado.

Para la estimación de la longitud, se evaluaron las técnicas: Función de Auto Correlación, Transformada de Radon y Cepstrum en una dimensión. Debido a que la longitud máxima del motion blur que se puede obtener es el valor del tamaño de la imagen (512), se estableció el límite de longitud de 95 píxeles para la experimentación, ya que este valor es mucho menor que el tamaño de la imagen. Para realizar la estimación de la longitud se estableció el ángulo de la $P S F$ en cero grados y se hicieron variaciones desde cinco hasta noventa y cinco píxeles con incrementos de un píxel. Luego se realizó un análisis con los errores absolutos promedio de cada una de las técnicas para la estimación del ángulo y la longitud de la difuminación, además, se elaboró un estudio comparativo entre las técnicas para determinar cuál de ellas presentaba mejores resultados respecto a los parámetros definidos anteriormente.

El algoritmo 1 presenta el paso a paso de la metodología usada para la evaluación de las técnicas para la estimación del ángulo y la longitud de la PSF.

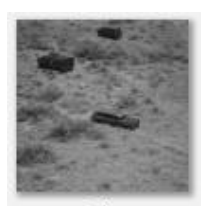

(a)

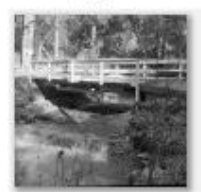

(i)

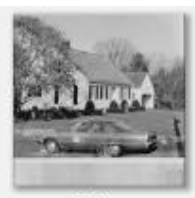

(b)

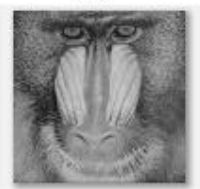

(j)

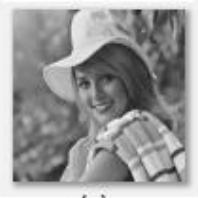

(c)

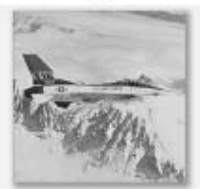

(k)

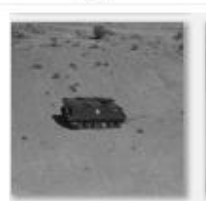

(q)

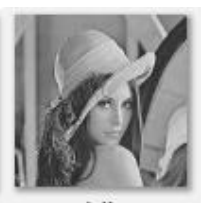

(d)

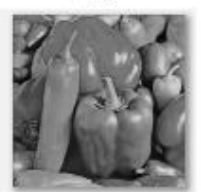

(I)

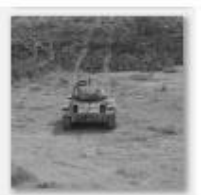

(r)

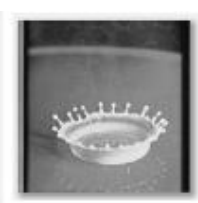

(e)

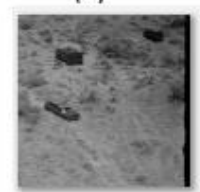

(m)

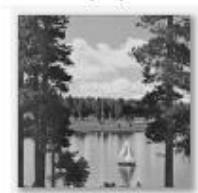

(s)

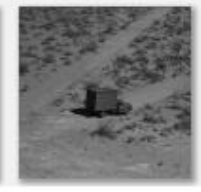

(f)

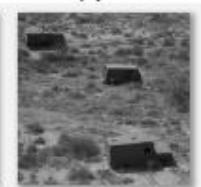

(n)

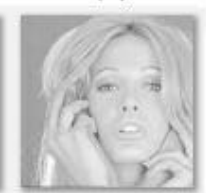

(t)

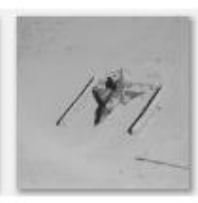

(g)

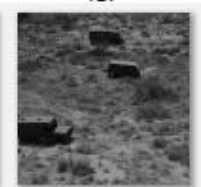

(o)

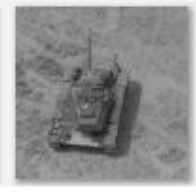

(h)

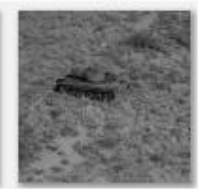

(p)

Fig. 10. Imágenes seleccionadas de la base de datos USC-SIPI usada para los experimentos. Fuente: [35]. 
Algoritmo 1. Metodología para la evaluación de las técnicas para la estimación del ángulo y la longitud de la PSF.

Paso 1. Para cada una de las 20 imágenes de la base de datos USC-SIPI.

Paso 2. Repetir desde $\theta=1$ hasta 90, con incremento de un grado. \{

Aplicar difuminación sintética a la imagen con $L=55$ pixeles a un ángulo $\theta$.

Evaluar cada método presentado para ángulo. Computar el error absoluto. \}

Paso 3. Leer nuevamente la imagen.

Paso 4. Repetir desde $L=5$ hasta 95, con incremento de un píxel. \{

Aplicar difuminación sintética a la imagen con $\theta=0$ a una longitud $L$.

Evaluar cada método presentado para longitud. Computar el error absoluto.\}

Paso 5. Realizar una comparación de los resultados de los métodos

\subsection{Evaluación de robustez al ruido}

El ruido puede estar presente en una imagen desde el mismo instante de captura de la imagen por la cámara debido a sensores defectuosos, errores en la transmisión de la señal por problemas en los canales de comunicación o el ruido térmico generado por los circuitos de la cámara. En esta investigación se considera el efecto del ruido sobre los métodos evaluados. Siendo el Ruido Aditivo Blanco Gaussiano (AWGN), el tipo de ruido más común en aplicaciones prácticas se seleccionó como modelo de ruido para evaluar la robustez de las técnicas frente al ruido [34]. Como el ruido mencionado es de tipo aditivo, se retoma (1).
Donde $g(x, y)$ es la imagen degradada, $h(x, y)$ es la PSF y $n(x, y)$ es el ruido aditivo sobre la imagen. Para este caso, el ruido añadido a la imagen es el Ruido Aditivo Blanco Gaussiano ( $A W G N$ ) presentado en (13):

$$
n(x, y)=\frac{1}{2 \pi \sigma^{2}} e^{-\left(\frac{x^{2}+y^{2}}{2 \sigma^{2}}\right)}
$$

Donde $n(x, y)$ es el $A W G N, x$ y $y$ son puntos de la imagen y $\sigma$ es la desviación estándar del ruido. Por facilidad en el manejo de los datos, el ruido se presenta como una relación señal a ruido, la cual es una medida que estima la calidad de una imagen comparada con la imagen no degradada; entre más alta la relación, el ruido tiene una menor intensidad. La calidad de una imagen se mide a partir del error medio cuadrático (MSE), cuya expresión matemática se presenta en (14).

$$
M S E=\frac{\sum_{x=1}^{M} \sum_{y=1}^{N}[f(x, y)-E(x, y)]^{2}}{M N}
$$

Donde $f(x, y)$ es la imagen base $\mathrm{y}$ $E(x, y)$ es la imagen con ruido, $\mathrm{M}$ y $\mathrm{N}$ son las columnas y las filas de las imágenes. Debido a que el Error Medio Cuadrático (MSE) depende del escalamiento de la intensidad de la imagen, esta relación es expresada en forma de una función logarítmica en unidades de decibeles para tratar de mantener una escala adecuada [36]. En (15) se presenta la conversión a decibles del MSE.

$$
P S N R=20 \log _{10}\left(\frac{255}{\sqrt{M S E}}\right) d B
$$

Donde PSNR es la Relación Señal a Ruido Pico de la imagen en decibeles y $M S E$ es el error medio cuadrático obtenido en (14). Para estimar la robustez al ruido de las técnicas, se degradaron las imágenes de prueba con AWGN en un intervalo de $20 \mathrm{~dB}$ a $36 \mathrm{~dB}$ con incrementos de $2 \mathrm{~dB}$. Una vez más, se evaluaron las técnicas para la 
Evaluación y comparación de técnicas para la reconstrucción de la función de dispersión de punto de imágenes degradadas por difuminación lineal uniforme

estimación del error promedio del ángulo y la longitud en presencia del ruido.

El algoritmo 2 presenta el paso a paso de la metodología usada para la evaluación de las técnicas para la estimación del ángulo y la longitud de la PSF presencia del ruido aditivo blanco gaussiano.

\subsection{Tiempos de ejecución}

Para estimar el tiempo promedio de ejecución de los métodos, se tomaron 100 iteraciones de cada algoritmo con una longitud de 55 píxeles y un valor de ángulo de 45 grados sobre la imagen Lenna como referencia. Todos los algoritmos realizados en esta investigación se ejecutaron sobre el programa MATLAB 2015a, en un equipo de cómputo de 64bits, 2GB de RAM con Windows 7 como sistema operativo y procesador Core i3. El algoritmo 3 presenta el paso a paso de la metodología usada para la evaluación de las técnicas para la estimación del tiempo de procesamiento.

Algoritmo 2. Metodología para la evaluación de las técnicas para la estimación del ángulo y la longitud de la PSF en presencia del ruido aditivo blanco gaussiano

Paso 1. Para cada una de las 20 imágenes de la base de datos USC-SIPI.

Paso 2. Repetir desde $\theta=1$ hasta 90 , con incremento de un grado.

\{

Aplicar difuminación sintética a la imagen con $L=55$ píxeles a un ángulo $\theta$.

Repetir desde $P S N R=20 d B$ hasta $36 \mathrm{~dB}$, con incremento de $2 d B$.

\{

Añadir ruido a la imagen degradada.

Evaluar cada método presentado para ángulo.

Computar el error absoluto.

\}

Paso 3. Leer nuevamente la imagen.

Paso 4. Repetir desde $\mathrm{L}=5$ hasta 95, con incremento de un píxel.

\{
Aplicar difuminación sintética a la imagen $\operatorname{con} \theta=0$ a una longitud $L$.

Repetir desde PSNR=20dB hasta $36 \mathrm{~dB}$, con incremento de $2 d B$.

\{

Añadir ruido a la imagen degradada.

Evaluar cada método presentado para longitud.

Computar el error absoluto.

\}

Paso 5. Realizar una comparación de los resultados de los métodos.

\section{Algoritmo 3. Metodología para la evalua- ción de las técnicas para la estimación del tiempo de procesamiento.}

Paso 1. Leer imagen.

Paso 2. Aplicar difuminación sintética a la imagen con $\mathrm{L}=55$ píxeles y $\theta=45$ grados.

Paso 3. Repetir desde i=1 hasta 100.

\{

Iniciar toma de medidas.

Evaluar cada método presentado para ángulo y longitud.

Finalizar toma de medidas.

\}

Paso 4. Promediar los tiempos de ejecución de cada una de las iteraciones de los métodos.

\section{RESULTADOS Y DISCUSIÓN}

Los resultados obtenidos en cada una de las pruebas para la estimación del ángulo y la longitud de la difuminación se mostrarán en la Fig. 11, 12, y 13.

En la Fig. 11 se puede apreciar que para las imágenes sin ruido los métodos de Hough y el filtro adaptativo Gabor tienen errores inferiores a 2 grados. Pero, el método de Hough presenta un pico en 90 grados que provoca un aumento en su error absoluto promedio.

En la Fig. 12 se aprecia que el método de Radon y Cepstrum 2D tienen resultados muy similares. Estos presentan un error absoluto promedio inferior a dos grados en la estimación del ángulo en todo el rango analizado; adicionalmente, ambos presen- 
Evaluación y comparación de técnicas para la reconstrucción de la función de dispersión de punto de imágenes degradadas por difuminación lineal uniforme

tan un error absoluto promedio considerable en los primeros ángulos, lo que provoca un aumento en su error. La razón por la cual algunos de los métodos tienen dificultades en 0 y en 90 grados, es porque al momento de realizar la transformada de Fourier de la imagen, se presenta una alta energía en el centro de la imagen debido a los bordes de la misma y llega tener un mayor peso que los demás contenidos de energía de la imagen. Esto se aprecia como una cruz brillante sobre y hacia el centro del espectro de Fourier, aunque se atenúa mediante el ventaneo Hanning.

En la Fig. 13 se puede apreciar que el método con mejor estimación es Cepstrum 1D. Sin embargo, se hace evidente un aumento en el error cuando aumenta la longitud de la difuminación. Lo anterior es debido a la dificultad de ubicar los ceros entre las líneas paralelas en el espectro de Fourier a medida que aumenta la longitud de la difuminación por movimiento, tal y como se ha explicado.

En la Fig. 14 se realiza una comparación de los métodos para la estimación del ángulo en presencia del Ruido Aditivo Blanco Gaussiano (AWGN), en la cual se puede observar que el método con mayor robustez para la estimación del ángulo es el Cepstrum 2D, con un error absoluto promedio inferior a 5 grados con una relación señal a ruido de $30 \mathrm{~dB}$.

En la Fig. 13 se puede apreciar que el método con mejor estimación es Cepstrum 1D. Sin embargo, se hace evidente un aumento en el error cuando aumenta la longitud de la difuminación. Lo anterior es debido a la dificultad de ubicar los ceros entre las líneas paralelas en el espectro de Fourier a medida que aumenta la longitud de la difuminación por movimiento, tal y como se ha explicado.

En la Fig. 14 se realiza una comparación de los métodos para la estimación del ángulo en presencia del Ruido Aditivo Blanco Gaussiano (AWGN), en la cual se puede observar que el método con mayor robustez para la estimación del ángulo es el Cepstrum 2D, con un error absoluto promedio inferior a 5 grados con una relación señal a ruido de $30 \mathrm{~dB}$.

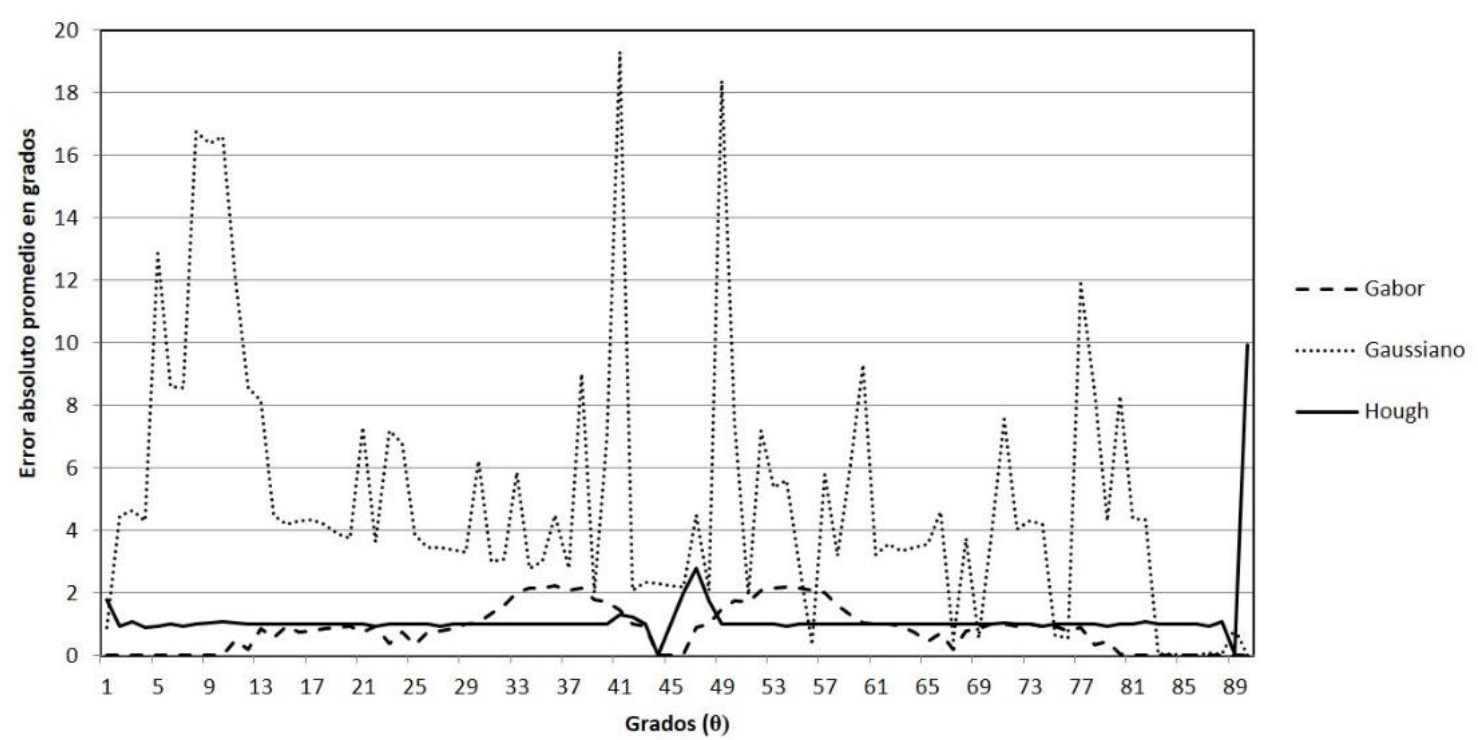

Fig. 11. Error absoluto promedio en grados para los métodos de filtros adaptativos Gaussiano, Gabor y Hough para la estimación del ángulo de la PSF. Fuente: autores. 
Evaluación y comparación de técnicas para la reconstrucción de la función de dispersión de punto de imágenes degradadas por difuminación lineal uniforme

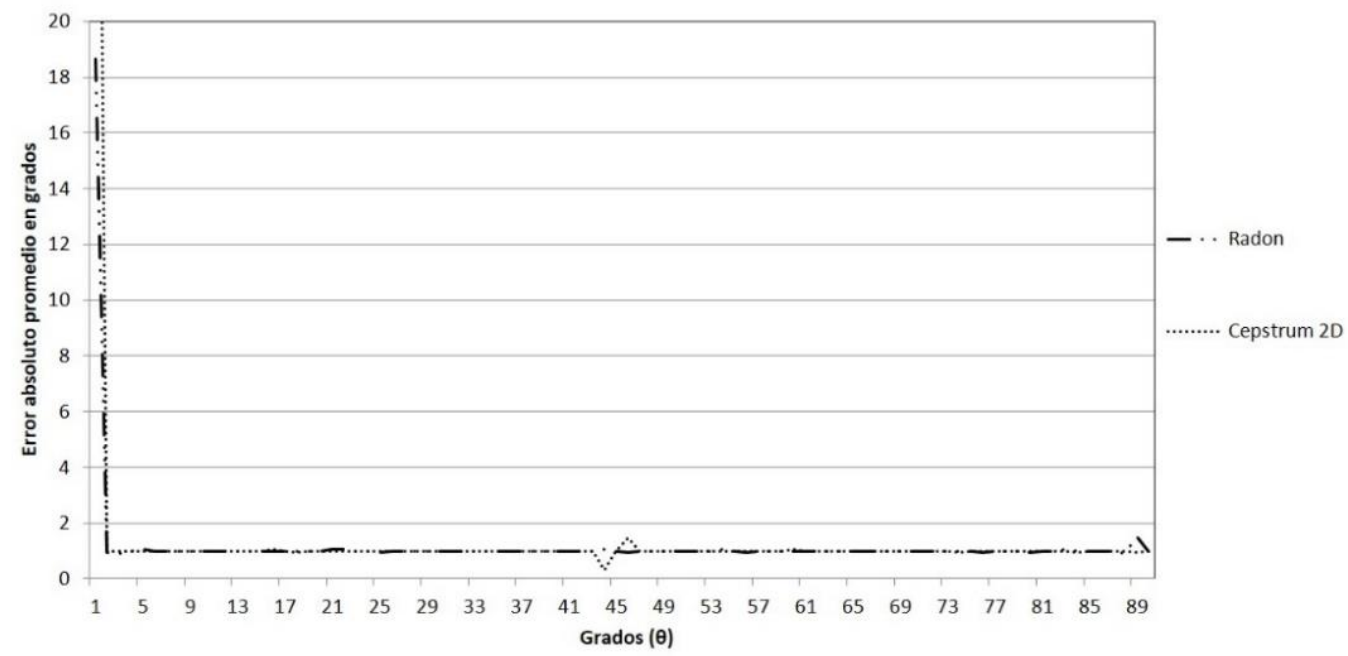

Fig. 12. Error absoluto promedio en grados para los métodos de Radon y Cepstrum 2D. Fuente: autores.

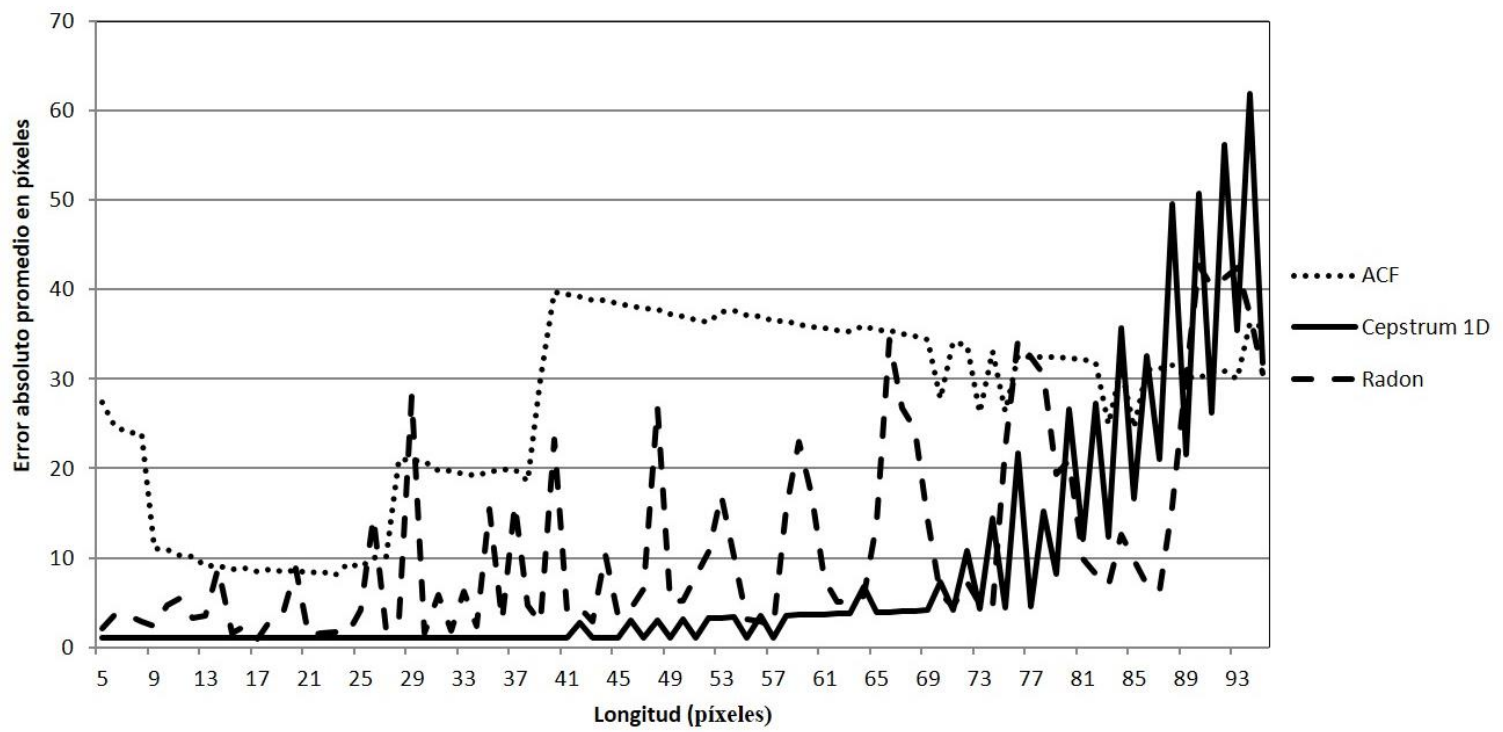

Fig. 13. Error absoluto promedio en píxeles para la estimación de la longitud en imágenes sin ruido. Fuente: autores. 
Evaluación y comparación de técnicas para la reconstrucción de la función de dispersión de punto de imágenes degradadas por difuminación lineal uniforme

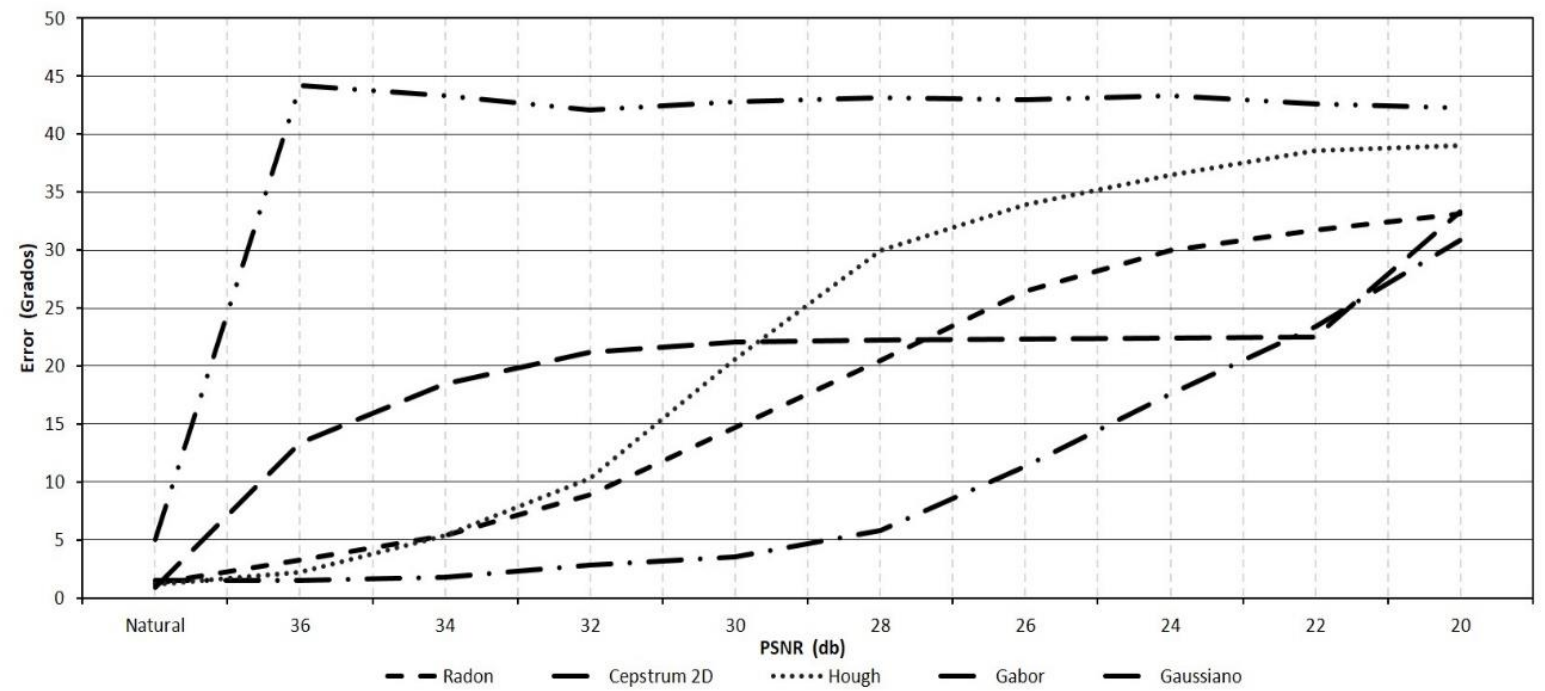

Fig. 14. Error absoluto promedio en grados para la estimación del ángulo en imágenes afectadas por ruido. Fuente: autores.

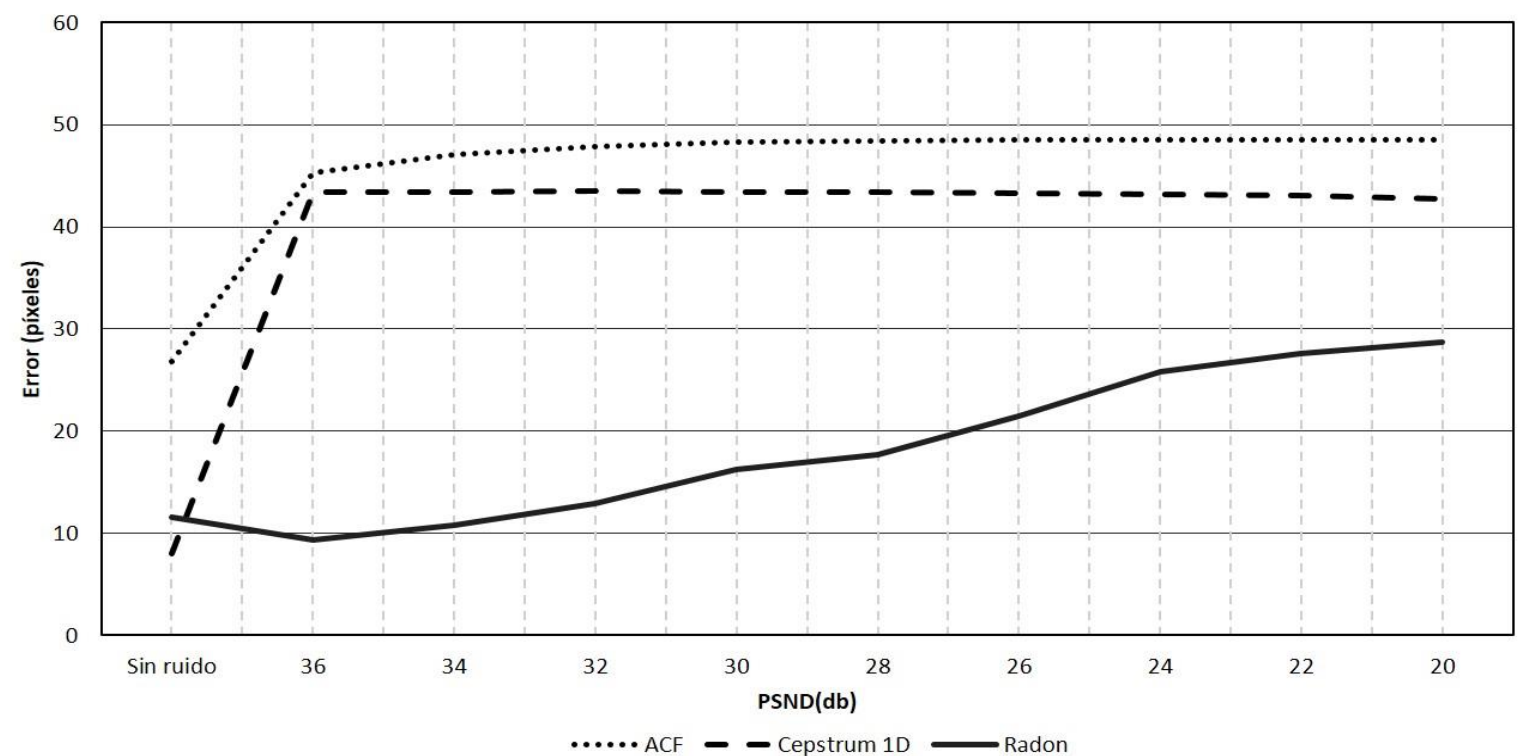

Fig. 15. Error absoluto promedio en píxeles para la estimación de la longitud en imágenes afectadas por ruido. Fuente: autores.

En la Fig. 15 se realiza una comparación de los métodos para la estimación de la longitud en presencia del Ruido Aditivo Blanco Gaussiano (AWGN), en la cual se puede observar que el método con menor error es la técnica de Radon, con un error absoluto promedio inferior a 20 píxeles con una relación señal a ruido de $28 \mathrm{~dB}$. No Obstante, se debe destacar que cuando la imagen no presenta ruido, el mejor método para la estimación de la longitud es el Cepstrum 1D con un error absoluto promedio inferior a 8 píxeles.

En la Fig. 16 se realiza una comparación del tiempo de ejecución de los métodos para la estimación del ángulo. En la cual se puede observar que el método con el que se obtuvo un resultado en el menor tiempo es la técnica del Hough. 
Evaluación y comparación de técnicas para la reconstrucción de la función de dispersión de punto de imágenes degradadas por difuminación lineal uniforme

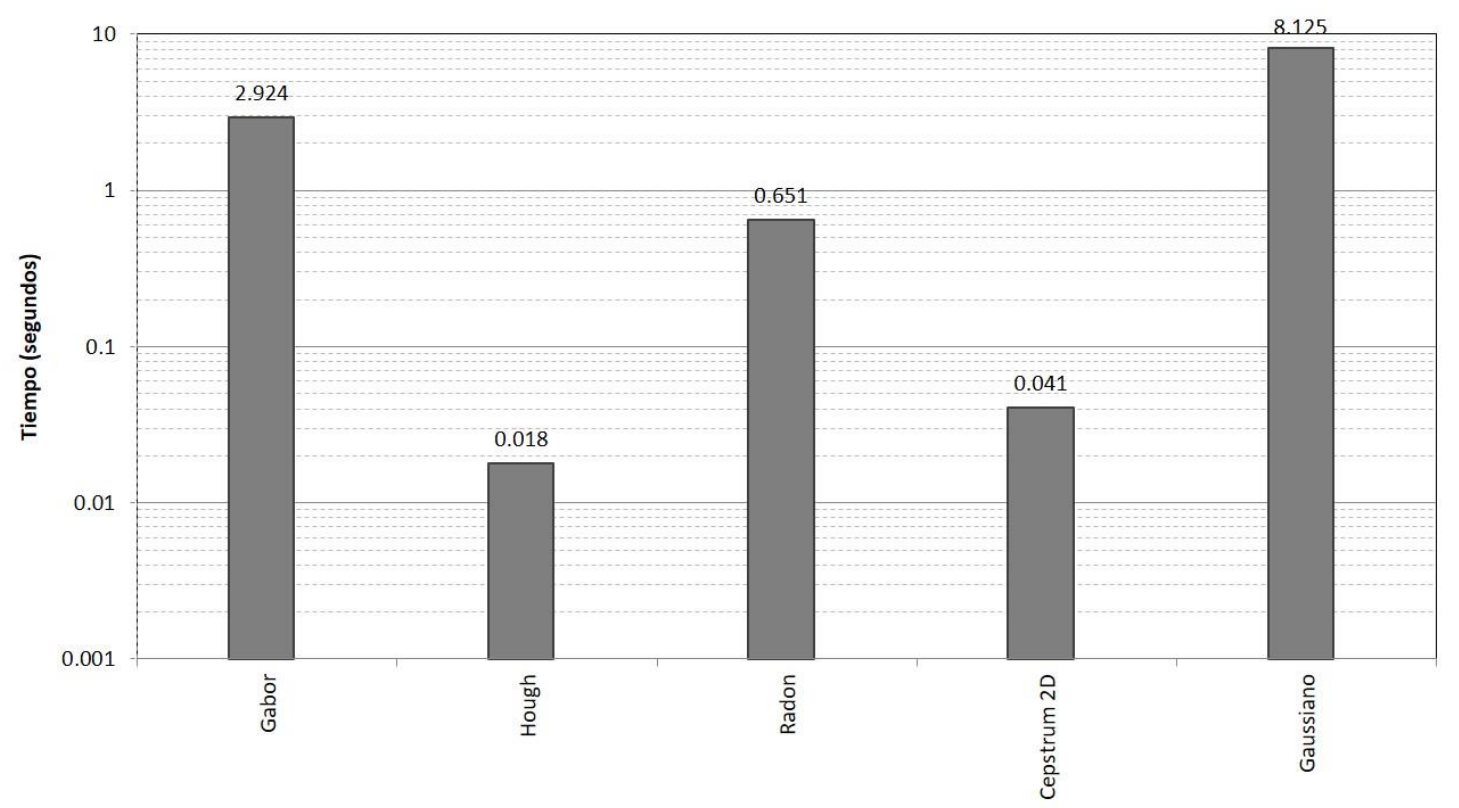

Fig. 16. Tiempo de ejecución de los métodos para la estimación del ángulo, Fuente: autores.

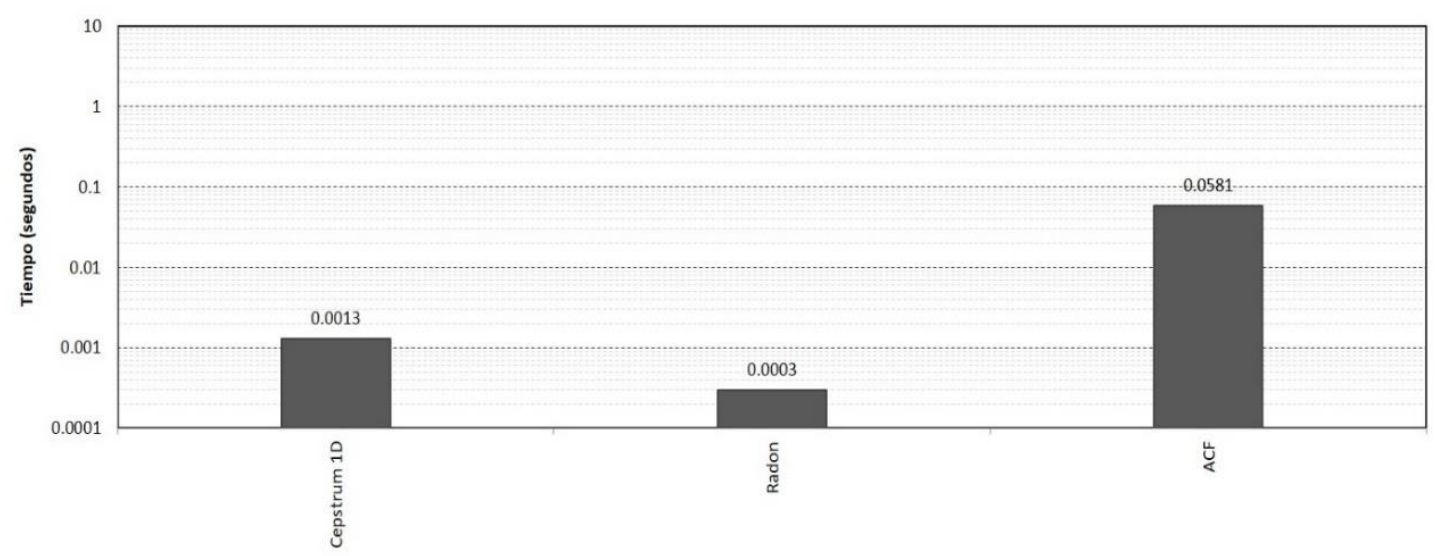

Fig. 17. Tiempo de ejecución de los métodos para la estimación de la longitud, Fuente: autores.

En la Fig. 17 se realiza una comparación del tiempo de ejecución de los métodos para la estimación de la longitud. Se puede observar que el método con el que se obtuvo un resultado en el menor tiempo es la técnica de Radon.

\section{CONCLUSIONES}

En este trabajo se introdujeron algunas técnicas representativas para la estimación de los parámetros de la PSF del desenfoque por movimiento lineal. Los resultados de- muestran que el método que presentó el menor Error Absoluto Promedio para la estimación del ángulo es el Filtro Adaptativo de Gabor con un error promedio de 0,84 grados. No obstante, el método de Cepstrum 2D mantuvo un error promedio de 1 grado en el intervalo de 5 a 90 grados con un tiempo de ejecución inferior a 0,1 segundos. De igual forma, esta última es la técnica más tolerante en presencia del Ruido Aditivo Blanco Gaussiano (AWGN) para la estimación del ángulo con un error promedio en $30 \mathrm{~dB}$ de 3,54 grados. De forma análoga, se evidenció que el método que

TecnoLógicas, ISSN-p 0123-7799 / ISSN-e 2256-5337, Vol. 21, No. 42, mayo-agosto de 2018, pp. 211-229 [227] 

degradadas por difuminación lineal uniforme

presentó el menor error para la estimación de la longitud es el Cepstrum 1D con un error promedio de 8,03 píxeles con un error estable de menos de 5 píxeles en el intervalo de 5 a 60 píxeles. Igualmente, se observó que la técnica que presentó con mayor tolerancia al ruido para la estimación de la longitud de la PSF en presencia del Ruido AWGN es la Transformada de Radón con un error promedio en $28 \mathrm{~dB}$ de 17,69 píxeles. Por último, la técnica que presentó menor tiempo de ejecución para la estimación del ángulo es Hough con un tiempo de 0,019 segundos y para la estimación de la longitud es la transformada de Radon con un tiempo de 0,0003 segundos. Por lo anterior, los autores recomiendan hacer uso de una técnica híbrida que realice el Cepstrum 2D para determinar el ángulo y el método del Cepstrum 1D para determinar la longitud de la PSF. Esta puede utilizarse, entre otras aplicaciones, para la restauración de la imagen degrada por movimiento, aunque que se encuentra fuera del alcance de este trabajo. Todos los métodos evaluados presentan importantes problemas de exactitud en la estimación del ángulo y la longitud en presencia de ruido. Por lo anterior, los autores consideran que se debe ahondar en el estudio de nuevas técnicas que resulten más tolerantes a sus efectos de degradación aún más evidentes si se trabaja con imágenes reales.

\section{REFERENCIAS}

[1] P. Doynov and S. P. Tankasala, "Ultrafast blur evaluation in ocular biometrics," in 2016 IEEE Symposium on Technologies for Homeland Security (HST), 2016, pp. 1-6.

[2] S. Saiyod, P. Wayalun, C. Khorinphan, J. Chaichawananit, and S. Boonkwang, "Motion blur parameter estimation based on autocorrelation for liver ultrasound image," in 2016 International Computer Science and Engineering Conference (ICSEC), 2016, pp. $1-6$.

[3] M. Lee, K.-S. Kim, and S. Kim, "Measuring Vehicle Velocity in Real Time using Modulated Motion Blur of Camera Image
Data," IEEE Trans. Veh. Technol., vol. 66, no. 5, pp. 3659-3673, 2017.

[4] A. Taherkhani and J. Mohammadi, "Object Speed Estimation in Frequency Domain of Single Taken Image," J. Basic Appl. Sci. Res., vol. 3, no. 1, pp. 120-124, 2013.

[5] M. Lee, K.-S. Kim, J. Cho, and S. Kim, "Development of a vehicle body velocity sensor using Modulated Motion Blur," in 2017 IEEE International Conference on Advanced Intelligent Mechatronics (AIM), 2017, pp. 406-411.

[6] C. Lyu, Y. Liu, X. Jiang, P. Li, and H. Chen, "High-Speed Object Tracking with Its Application in Golf Playing," Int. J. Soc. Robot., vol. 9, no. 3, pp. 449-461, Jun. 2017.

[7] C. H. Wu, K. Tseng, C. K. Ng, and W. H. Ip, "An effective motion-blurred image restoration approach for automated optical inspection," HKIE Trans., vol. 22, no. 4, pp. 252-262, Oct. 2015.

[8] Y. Yitzhaky and N. S. Kopeika, "Identification of blur parameters from motion blurred images," Graph. Model. image Process., vol. 59, no. 5, pp. 310-320, 1997.

[9] A. M. Deshpande and S. Patnaik, "Radon transform based uniform and non-uniform motion blur parameter estimation," in 2012 International Conference on Communication, Information \& Computing Technology (ICCICT), 2012, pp. 1-6.

[10] R. Lokhande, K. V Arya, and P. Gupta, "Identification of parameters and restoration of motion blurred images," in Proceedings of the 2006 ACM symposium on Applied computing - SAC '06, 2006, pp. 301-305.

[11] I. M. Rekleitis, "Steerable filters and cepstral analysis for optical flow calculation from a single blurred image," in Vision Interface, 1996, vol. 1, pp. 159-166.

[12] A. M. Deshpande and S. Patnaik, "A novel modified cepstral based technique for blind estimation of motion blur," Opt. - Int. J. Light Electron Opt., vol. 125, no. 2, pp. 606615, Jan. 2014.

[13] J. Park, M. Kim, S. Chang, and K. H. Lee, "Estimation of motion blur parameters using cepstrum analysis," in 2011 IEEE 15th International Symposium on Consumer Electronics (ISCE), 2011, pp. 406-409.

[14] R. Mamta and M. Dutta, "GA based Blind Deconvolution Technique of Image Restoration using Cepstrum Domain of Motion Blur," Indian J. Sci. Technol., vol. 10, no. 16, pp. 1-8, Apr. 2017.

[15] L. Xu, X. Gao, and T. Fang, "Automatic restoration of motion blurred image based on frequency and cepstrum domain," in $A O P C$ 2015: Image Processing and Analysis, 2015, 
Evaluación y comparación de técnicas para la reconstrucción de la función de dispersión de punto de imágenes degradadas por difuminación lineal uniforme

[16] M. J. Shah and U. D. Dalal, "Blind estimation of motion blur kernel parameters using Cepstral domain and Hough transform," in 2014 International Conference on Advances in Computing, Communications and Informatics (ICACCI), 2014, pp. 992997.

[17] M. J. Shah and U. D. Dalal, "Hough transform and cepstrum based estimation of spatial-invariant and variant motion blur parameters," in 2014 International Conference on Advances in Electronics Computers and Communications, 2014, pp. $1-6$.

[18] R. Dash, P. K. Sa, and B. Majhi, "Blur parameter identification using support vector machine," ACEEE Int J Control Syst Instrum, vol. 3, no. 2, pp. 54-57, 2012.

[19] S. Tiwari, V. P. Shukla, S. R. Biradar, and A. K. Singh, "Blind Restoration of Motion Blurred Barcode Images using Ridgelet Transform and Radial Basis Function Neural Network," ELCVIA Electron. Lett. Comput. Vis. Image Anal., vol. 13, no. 3, pp. 63-80, Dec. 2014.

[20] A. Kumar, "Deblurring of motion blurred images using histogram of oriented gradients and geometric moments," Signal Process. Image Commun., vol. 55, pp. 55-65, Jul. 2017.

[21] Z. Wang, Z. Yao, and Q. Wang, "Improved scheme of estimating motion blur parameters for image restoration," Digit. Signal Process., vol. 65, pp. 11-18, Jun. 2017.

[22] S. Jayaraman, S. Esakkirajan, and T. Veerakima, Digital image processing, 3rd ed. Tata McGraw-Hill Education, 2009.

[23] T. Acharya and A. K. Ray, Image Processing: Principles and Applications. Hoboken, NJ, USA: John Wiley \& Sons, Inc., 2005.

[24] M. Cannon, "Blind deconvolution of spatially invariant image blurs with phase," IEEE Trans. Acoust., vol. 24, no. 1, pp. 58-63, Feb. 1976.

[25] R. Dash and B. Majhi, "Motion blur parameters estimation for image restoration," Opt. - Int. J. Light Electron Opt., vol. 125, no. 5, pp. 1634-1640, Mar. 2014.
[26] N. Phansalkar, "Determination of linear motion point spread function using Hough transform for image restoration," in 2010 IEEE International Conference on Computational Intelligence and Computing Research, 2010, pp. 1-4.

[27] J. Mohammadi, R. Akbari, and M. K. Ba haghighat, "Vehicle speed estimation based on the image motion blur using RADON transform," in 2010 2nd International Conference on Signal Processing Systems, 2010, vol. 1, pp. V1-243-V1-247.

[28] W. T. Freeman and E. H. Adelson, "The design and use of steerable filters," IEEE Trans. Pattern Anal. Mach. Intell., vol. 13, no. 9, pp. 891-906, 1991.

[29] D. Bhattacharya, J. Devi, and P. Bhattacherjee, "Brain image segmentation technique using Gabor filter parameter," Am. J. Eng. Res., vol. 2, no. 9, pp. 127-132, 2013.

[30] V. S. N. Prasad and J. Domke, "Gabor filter visualization,” J. Atmos. Sci, vol. 13, 2005.

[31] Y. Yitzhaky, I. Mor, A. Lantzman, and N. S. Kopeika, "Direct method for restoration of motion-blurred images," J. Opt. Soc. Am. A, vol. 15, no. 6, pp. 1512-1519, 1998.

[32] S. Tiwari, V. P. Shukla, and A. K. Singh, "Certain investigations on motion blur detection and estimation," in Proceedings of international conference on signal, image and video processing, IIT Patna, 2012, pp. 108114.

[33] M. Dobeš, L. Machala, and T. Fürst, "Blurred image restoration: A fast method of finding the motion length and angle," Digit. Signal Process., vol. 20, no. 6, pp. 1677-1686, Dec. 2010.

[34] S. Tiwari, V. P. Shukla, A. K. Singh, and S. R. Biradar, "Review of Motion Blur Estimation Techniques," J. Image Graph., vol. 1, no. 4, pp. 176-184, 2014.

[35] University of Southern California - USC, "The USC-SIPI Image Database." [Online]. Available:

http://sipi.usc.edu/database/database.php?vol ume $=$ misc

[36] M.-M. Sung, H.-J. Kim, E.-K. Kim, J.-Y. Kwak, J.-K. Yoo, and H.-S. Yoo, "Clinical evaluation of JPEG2000 compression for digital mammography," IEEE Trans. Nucl. Sci., vol. 49, no. 3, pp. 827-832, 2002. 